\title{
Saberes de idosos moradores do meio rural sobre o envelhecimento saudável e ativo
}

\author{
Knowledge of rural elderly residents about healthy and active aging \\ Conocimiento de los ancianos rurales sobre el envejecimiento sano y activo
}

Recebido: 28/09/2021 | Revisado: 03/10/2021 | Aceito: 05/10/2021 | Publicado: 09/10/2021

\author{
Angélica Zanettini Konrad \\ ORCID: https://orcid.org/0000-0003-1712-9073 \\ Universidade Comunitária da Região de Chapecó, Brasil \\ E-mail: angeliica.zanettini@gmail.com \\ Fátima Ferretti \\ ORCID: https://orcid.org/ 0000-0002-0326-2984 \\ Universidade Comunitária da Região de Chapecó, Brasil \\ E-mail:ferrettifisio@yahoo.com.br \\ Vanessa da Silva Corralo \\ ORCID: https://orcid.org/0 000-0003-4234-4875 \\ Universidade Comunitária da Região de Chapecó, Brasil \\ E-mail: vcorralo@unochapeco.edu.br \\ Kátia Lilian Sedrez Celich \\ ORCID: https://orcid.org/0000-0002-5166-8444 \\ Universidade Federal Fronteira Sul, Brasil \\ E-mail: katia.celich@uffs.edu.br
}

\begin{abstract}
Resumo
Introdução: os saberes de idosos moradores do meio rural são construídos por meio da experiência vivida, a partir das relações com o contexto e a comunidade, perpassando valores, crenças e inquietudes. Objetivo: conhecer os saberes de idosos moradores do contexto rural de um município do oeste catarinense quanto ao envelhecimento saudável e ativo. Metodologia: Trata-se de um estudo qualitativo, que utilizou a história oral temática como método. Participaram da pesquisa, seis idosos com 70 anos ou mais, moradores do contexto rural e que atingiram pontuação adequada no Mini Exame de Estado Mental (MEEM). A análise dos dados foi realizada por meio da análise temática de conteúdo, conforme Minayo (2014). Resultados e Discussões: dentre os saberes estabelecidos encontram-se a constância do trabalho no meio rural como uma estratégia de manutenção de um perfil ativo nas atividades do dia a dia, além de demarcarem também a importância da utilização de plantas medicinais no cuidado a saúde, bem como, das informações adquiridas nos meios de comunicação e pelos profissionais de saúde. Conclusão: os saberes sobre envelhecimento saudável e ativo dos idosos foram construídos ao longo da trajetória de vida, impregnados de historicidades, constituídos pelas relações sociais, crenças, valores e forte sentimento de pertencimento e de amor e de ligação com o contexto em que vivem.
\end{abstract}

Palavras-chave: Envelhecimento saudável; Idoso; Zona rural.

\begin{abstract}
Introduction: the knowledge of elderly people living in rural areas is built through the lived experience, from the relationships with the context and the community, permeating values, beliefs and concerns. Objective: to know the knowledge of elderly people living in the rural context of a municipality in western Santa Catarina regarding healthy and active aging. Methodology: This is a qualitative study, which used thematic oral history as a method. Six elderly people aged 70 years or more, living in the rural context and who achieved adequate scores on the Mini Mental State Examination (MMSE) participated in the research. Data analysis was performed through thematic content analysis, according to Minayo (2014). Results and Discussions: among the established knowledge is the constancy of work in rural areas as a strategy to maintain an active profile in daily activities, in addition to demarcating the importance of using medicinal plants in health care, as well as the information acquired in the media and by health professionals. Conclusion: the knowledge about healthy and active aging of the elderly was built throughout their life trajectory, impregnated with historicities, constituted by social relationships, beliefs, values and a strong sense of belonging and love and connection with the context in which they live.
\end{abstract}

Keywords: Healthy aging; Age; Rural areas.

\section{Resumen}

Introducción: el conocimiento de las personas mayores que viven en zonas rurales se construye a través de la experiencia vivida, a partir de las relaciones con el contexto y la comunidad, permeando valores, creencias e inquietudes. Objetivo: conocer el conocimiento de las personas mayores que viven en el contexto rural de un municipio del occidente de Santa Catarina sobre el envejecimiento saludable y activo. Metodología: Se trata de un 
estudio cualitativo, que utilizó como método la historia oral temática. En la investigación participaron seis personas mayores de 70 años o más, residentes en el contexto rural y que obtuvieron puntajes adecuados en el Mini Examen del Estado Mental (MMSE). El análisis de datos se realizó mediante análisis de contenido temático, según Minayo (2014). Resultados y Discusiones: entre los conocimientos establecidos se encuentra la constancia del trabajo en el medio rural como estrategia para mantener un perfil activo en las actividades diarias, además de demarcar la importancia del uso de plantas medicinales en el cuidado de la salud, así como la información adquirida en la medios de comunicación y profesionales de la salud. Conclusión: el conocimiento sobre el envejecimiento saludable y activo de las personas mayores se construyó a lo largo de su trayectoria vital, impregnado de historicidades, constituido por relaciones sociales, creencias, valores y un fuerte sentido de pertenencia y amor y conexión con el contexto en el que viven.

Palabras clave: Envejecimiento saludable; Anciano; Medio rural.

\section{Introdução}

O envelhecimento humano é um processo natural e inevitável, que integra aspectos multifatoriais e multidimensionais, que produzem modificações biológicas e fisiológicas no indivíduo, influenciadas pelos aspectos sociais, econômicos, psicológicos, ecológicos, culturais e espirituais (Mendes; Soares; Massi, 2015). Portanto, a realidade socioeconômica e cultural, bem como o lugar e o meio em que cada um envelhece, acarretam diferentes modos de ser e viver essa fase da vida. Essa nova realidade tem colocado como desafio a necessidade de conhecer como as pessoas idosas vivem essa fase, analisando o que pode ser realizado ao longo do percurso da vida, com o intuito de chegar à velhice com qualidade e dignidade (Valer, 2015).

Garbaccio et al. (2018) afirmam que o processo de envelhecer da população rural é caracterizado por restrição do acesso ao transporte, distância dos recursos sociais e de saúde, más condições das estradas, de renda e do próprio hábito dos idosos em buscar assistência curativa/terapêutica e não preventiva. Por outro lado, Winckler et al., (2016) destaca que os idosos que vivem no meio rural mantêm uma rede de relações sociais e de parentesco mais fortalecida e o trabalho por maior tempo, o que dá sentido à sua vida. Além disso, são mais ativos, visto que, mesmo depois de aposentados, continuam a desenvolver as atividades cotidianas, como o cuidar dos animais, da plantação e do entorno, aspectos que podem constituir-se em fator de proteção.

O envelhecimento ativo, conforme preconizado pela Organização Pan-Americana de Saúde (OPAS), é entendido com um processo que deveria otimizar as oportunidades de saúde, de participação social e de segurança, com o objetivo de manter as pessoas mais autônomas e independentes, com melhor qualidade de vida (Opas, 2005).

No mesmo sentido, a Política Nacional de Saúde da Pessoa Idosa (PNSPI) enfatiza que a finalidade das ações na área da saúde, quando se trata do cuidado a esse segmento populacional, é a de buscar a promoção da autonomia, independência, integração e participação efetiva na sociedade, visando o exercício da cidadania e o atendimento de suas necessidades, com medidas coletivas e individuais de saúde para esse fim, em diferentes níveis de atenção do SUS (Brasil, 2006). Do mesmo modo, a revisão integrativa de Tavares et al. (2017), que buscou analisar a perspectiva de idosos sobre o envelhecimento saudável, evidenciou um olhar relacionado a diferentes dimensões, como a adoção de hábitos e comportamentos saudáveis com autorresponsabilidade, o sentimento de otimismo, a reciprocidade no apoio social e a capacidade de viver com autonomia e independência.

Para a área da saúde são grandes os desafios, já que os idosos apresentam mais comorbidades, doenças crônicas e incapacidades funcionais, com necessidade de cuidados e tratamentos diferenciados, o que resulta no uso prolongado dos serviços de saúde ocasionando maiores gastos ao sistema (Granerud; Imingen; Eriksson, 2017; Veras; Peixoto, 2018). Nessa direção, todas as ações que podem promover o envelhecimento saudável e ativo são fundamentais.

Envelhecer de modo ativo, com possibilidades de participação social acompanhada de melhorias nas condições de saúde e cuidado, se dão permeadas pelos saberes, atitudes e práticas adotadas pelos idosos ao longo da vida, aspectos 
fundamentais quando se quer agregar qualidade a longevidade. Nesta pesquisa o conceito de saberes está vinculado aos conhecimentos construídos e/ou elaborados sobre a experiência vivida, a partir das suas relações com o contexto e a comunidade, e que perpassam por valores, crenças e inquietudes (Cruz et al., 2018). Como Freire (2019) já enfatizava, os saberes são conhecimentos construídos com base nas experiências e prática de vida comunitária e nas relações que estabelecem entre "homem-mulher-mundo". Reforça também que o sujeito precisa se construir e reconstruir continuamente, com reflexões sobre a realidade, pois ela nunca é apenas o fato objetivo, o fato real, mas também é composta pela sua percepção (Freire, 1984).

Os comportamentos que assumimos ao longo de nossa vida estão pautadas nos diferentes saberes e crenças que possuímos, são influenciadas pelas aprendizagens construídas no decorrer do percurso de vida de cada um, conforme o contexto comunitário ou social que se insere e se desenvolve enquanto pessoa (Tafuri; Gonçalves Junior, 2017). Para Paulo Freire (2019) as práticas e as atitudes são conscientes no ser humano, implicam em reflexão, intencionalidades e temporalidades, de acordo com as relações e o ambiente em que vivem, logo, os humanos podem refletir sobre suas limitações e projetar ações para transformar a realidade que os condiciona e viver de forma mais saudável. Portanto, parece-nos que dar voz aos idosos para que por meio da história oral possam partilhar aspectos da sua trajetória de vida, com seus hábitos, histórias, atitudes e saberes construídos no percurso de viver e envelhecer no meio rural, pode estimular a prática de ações para um envelhecimento bem-sucedido. Considerando esse contexto o presente estudo se propôs a conhecer os saberes de idosos moradores do contexto rural de um município do oeste catarinense quanto ao envelhecimento saudável e ativo.

\section{Metodologia}

Trata-se de uma pesquisa de abordagem qualitativa, pautada no método da história oral temática, que busca compreender as experiências dos sujeitos frente a determinados fenômenos. Esta se configura como uma abordagem metodológica de natureza interdisciplinar que abrange tanto a compreensão e a interpretação das vidas individuais, quanto à análise de grupos específicos sobre um determinado tema (Thompson, 2002; Meihy; Holanda, 2007).

O estudo contou com a participação de seis idosos, sendo três do sexo masculino e três do sexo feminino, com idade entre 70 a 75 anos que foram denominados de colaboradores, conforme preconiza o método (Meihy; Holanda, 2007). Os critérios de seleção dos colaboradores foram idosos com 70 anos ou mais, de ambos os sexos, que sempre residiram no contexto rural e que apresentavam estado cognitivo preservado, testado pelo Mini Exame do Estado Mental (MEEM).

A coleta dos dados foi organizada no meio rural, com base nos cinco distritos rurais de um município do oeste de Santa Catarina. Para dar início ao processo de localização dos colaboradores foram sorteados aleatoriamente dois distritos. Logo após, foi realizada uma visita aos líderes das comunidades sorteadas para apresentar o projeto, sua finalidade e o modo de coleta de dados. A aproximação inicial da pesquisadora com os colaboradores ocorreu por meio de duas a três visitas, sendo que foi ofertado assistência por meio de uma consulta de enfermagem aos idosos, para promover uma maior proximidade, segurança, confiança e sintonia entre pesquisador e idoso.

Posteriormente, a pesquisadora esclareceu o objetivo e a finalidade do estudo, bem como, todas as etapas da pesquisa, desde a coleta de dados até a devolutiva. Os idosos que aceitaram participar da pesquisa assinaram o Termo de Consentimento Livre e Esclarecido (TCLE) e Termo de Consentimento para uso de imagem e voz.

A coleta de dados foi realizada no período compreendido entre novembro de 2020 a fevereiro de 2021. Os dados foram coletados por meio de uma entrevista em profundidade com questões divididas em duas etapas que incluíam questões sobre a trajetória de vida no meio rural, suas rotinas, seus conhecimentos e saberes sobre envelhecer de modo saudável e ativo e suas reflexões quanto ao tema. As entrevistas ocorreram no domicílio do idoso, com duração de aproximadamente três horas. Foram seguidas todas orientações do Ministério da Saúde (MS) quanto aos cuidados de higiene e distanciamento em função da 
pandemia por Covid-19.

Todas as etapas da entrevista foram transcritas e validadas no encontro subsequente, possibilitando que eles pudessem adicionar, excluir ou modificar elementos, caso julgassem necessário (Meihy; Holanda, 2007). A fim de garantir o sigilo e o anonimato, os colaboradores foram identificados por pseudônimos, nomes de flores que eles próprios indicaram. Salienta-se que a pesquisa só teve início após a aprovação no Comitê de Ética em Pesquisa envolvendo Seres Humanos, sob o parecer $\mathrm{n}^{\circ} .4 .450 .614$.

Para a construção da história oral foram seguidas três etapas conforme preconiza Meihy e Holanda (2007), a primeira de transcrição, a segunda da textualização e a terceira de transcriação. Os dados foram analisados de acordo com a análise temática de conteúdo, conforme proposição de Minayo (2014), com a pré-análise, composta da leitura flutuante e exaustiva do material coletado; exploração do material, com categorização da análise temática, buscando uma compreensão do texto e categorizando as palavras e expressões significativas obtidas, seguida da interpretação do material e discussão das categorias com referencial teórico.

\section{Resultados e Discussão}

A pesquisa realizada teve a participação de seis idosos, de ambos os sexos, residentes no ambiente rural. A média de

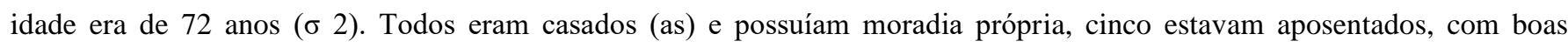
condições de alimentação e saneamento básico.

Após análise de conteúdo temático das histórias orais, surgiram quatro categorias analíticas relativas aos saberes construídos pelos idosos no seu percurso de vida quanto ao envelhecimento saudável e ativo que serão apresentadas na sequência.

\section{Saberes construídos no curso da vida quanto ao envelhecimento saudável e ativo: o meio rural em destaque}

Entende-se como saberes os conhecimentos construídos e/ou elaborados sobre a experiência vivida, por meio das relações com o contexto e a comunidade, perpassados por valores, crenças e inquietudes (Cruz et al., 2018). Conforme Freire (2019) os saberes e fazeres são conhecimentos que se constroem por meio da interação entre os envolvidos, a partir de uma práxis mediada pelo diálogo e pelas experiências de vida comunitária, constituída nas relações entre "homem-mulher-mundo", resultantes em um pensamento crítico.

No que tange os saberes construídos pelos idosos do contexto rural sobre o envelhecimento saudável, parece-nos que há uma forte relação com o local onde residem, uma identidade construída por meio do sentido de pertencimento ao meio rural e a vontade de lá permanecer, o que influencia profundamente o modo de perceber esse envelhecimento saudável e bemsucedido, conforme demonstrado nos seguintes depoimentos:

"Acredito que o meio rural seja o lugar mais adequado e saudável para os idosos, porque aqui não tem as frescuras da cidade, aqui você tem o teu cantinho, é daqui, conhece todo mundo, mantemos alguns costumes como, por exemplo, de se visitar, temos mais liberdade, o ar é mais limpo eu digo que a água até é melhor" (Girassol, 75 anos).

"Eu gosto de morar aqui no meio rural, para sair daqui só me levando, eu pertenço a esse lugar, gosto porque nasci aqui e para mim é importante ficar em um lugar só, realizando os seus objetivos, por isso que eu acho que a partir do momento que você se instala e se realiza é tudo, neste lugar criei meus laços desde jovem, com os vizinhos, com a comunidade, aqui tenho muitas recordações e lembranças" (Cravo, 73 anos).

"Pra mim o meio rural é vida, eu vivo nesse meio e aqui vai ser o lugar do meu fim também, porque quando fui 
parar um tempinho na cidade, na casa da filha para ajudar, quando ela teve os nenês, não gostei nenhum um pouco [...]. Por isso eu gosto de tudo aqui, de ver as minhas coisas, olhar quantas vezes for preciso, mexer na terra, essa sempre foi minha paixão, esse é meu lugar" (Violeta, 71 anos).

De acordo com Cavalcanti e Santos (2017) esse sentimento de pertencimento e identidade são indissociáveis, visto que se constituem por diferentes processos e se relacionam com os sentimentos, valores, significados e sentidos produzidos pelas interações das pessoas nos locais onde vivem.

O sentimento de pertencimento é determinado pela segurança emocional, está relacionada à construção de vínculos afetivos com o lugar e com o compartilhamento de ideias e práticas com outros da mesma realidade social e cultural. No contexto rural está associada às atividades relacionadas ao cultivo da terra, os costumes em comunidade, a rede de relações sociais e o modo de viver nesse contexto (Cavalcanti; Santos, 2017), são saberes informais construídos no cotidiano, no dia a dia.

Segundo Smith (1996), os saberes/educação formal é constituída pelo desenvolvimento da capacidade intelectual, por meio da educação oferecida nas escolas, em cursos e programas, embora essas produções do conhecimento não se restrinjam somente a instituições ou a lugares determinados. Já os saberes/educação informal não ocorrem em lugares e horários preestabelecidos, os conhecimentos são compartilhados por meio de uma interação sociocultural, tendo como única condição, haver quem saiba e quem queira saber, ocorrendo espontaneamente.

Dentre os saberes construídos ao longo da vida, permeados por esse sentido de pertencer e amor ao local onde vivem, após análise de conteúdo temática, emergiram três categorias, duas mais pautadas nos saberes informais, que são a ideia de trabalhar ao longo da vida para manter-se ativo e saudável e cuidado com plantas medicinais e uma vinculada ao saber formal, que está centrada na ideia de gerir o autocuidado.

\section{Trabalhar ao longo da vida para manter-se ativo: saber repassado de geração em geração}

Os idosos, ao longo de suas vidas, vão aprendendo e formulando um conjunto de saberes, construído a partir de suas vivências e experiências de vida. Guimarães e Pinheiro (2018) acrescentam que os conhecimentos/saberes são gerados em condições singulares, a partir de cada família, por meio da orientação de atividades relacionadas a questões culturais, econômicas e ao modo de vida, passado de geração para geração entre as famílias.

Um desses saberes está relacionado ao trabalho no meio rural, advindo de herança familiar como uma atividade essencial desempenhada por eles, conforme as falas a seguir:

\footnotetext{
"Eu tive alguns ensinamentos que aprendi com o meu pai, por exemplo, a cuidar da criação de porcos, a fazer o salame e cuidar dos animais, o lidar com o plantio e colheita e sempre se manter no trabalho, que isso é bom e importante" (Begônia, 73 anos).

"Aprendi muito com o meu pai, principalmente o trabalho na lavoura, ele era uma pessoa extremamente calma, eu gostaria de ter a calma e a disposição para o trabalho que ele tinha” (Cravo, 73 anos).
}

Nas falas acima, observa-se conhecimentos herdados pela família, como o lidar na lavoura, criação de animais, manipulação de alimentos, deixando claro que o modo de desempenhar o trabalho era passado de geração para geração, características tradicionais do meio rural que permanecem vivas nas práticas diárias.

O trabalho é definido na sociedade como um elemento fundamental, principalmente no que se refere ao contexto social desses idosos, pois, transcende as necessidades relacionadas à renda, mas atribui o significado de reconhecimento, de ter um papel social na comunidade, portanto de desenvolvimento pessoal, o que interfere no processo saúde e doença (Costa et al., 2016).

Em uma pesquisa realizada por Ferraz, Alves e Ferretti (2017) com 10 idosos agricultores de um município de Santa 
Catarina foi observado que o trabalho para os idosos rurais representava a continuidade do seu papel na família e de um status de manter-se ativo, com vigor e força para o trabalho braçal.

Conforme as falas a seguir são notórios os desejos de se manter ativo e trabalhando, principalmente pelos exemplos que obtiveram na família, relacionando o trabalho com autonomia, independência e saúde:

"Acredito que todas essas atividades que aprendi ao longo da vida são muito importantes pra minha saúde, eu tive um espelho com os meus tios, que se aposentaram e se sentaram na área da casa, duram uns três a quatro anos só [...] não conseguiam mais nem andar, caminhavam da sala até a cozinha [...] e o meu pai, trabalhou até quatro meses antes dele falecer, ele tinha uma lavoura grande, ele juntamente com a mãe quebravam todo o milho, carpiam toda a roça, saiam logo no clarear do dia [...] passou a vida trabalhando, sempre na ativa. Por isso decidi, sigo o rumo do pai, não dos meus tios" (Cravo, 73 anos).

"Meu pai, um exemplo de vida e persistência, levou os filhos com orientação e firmeza, hoje ele está com 94 anos [...] minha meta é dura que nem ele, porque ele ainda se vira, é independente e saudável, trabalhou a vida toda [...]” (Rosa, 70 anos).

Em uma revisão internacional da literatura com o intuito de avaliar a relação saúde-aposentadoria em países desenvolvidos, evidenciou-se a associação entre manter-se ativo no trabalho e a manutenção da saúde, uma vez que a aposentadoria precoce está associada com diminuição da capacidade física, psicológica e cognitiva, além de influenciar diretamente na autonomia, independência e apoio social (French; Jones, 2017).

Farias e Santos (2012) destacam que os determinantes do envelhecimento ativo devem ser atribuídos como metas a serem alcançadas ao longo da vida de todos os indivíduos, a fim de garantir que o envelhecimento seja permeado pela independência e autonomia. As autoras ressaltam ainda, que evidências de um envelhecimento ativo são constatadas quando os idosos se tornam longevos e independentes, com possibilidades de participação social acompanhada de melhorias nas condições de saúde e autocuidado, mantidas pelos saberes e práticas adotadas pelos idosos ao longo da vida.

Nesse sentido, a manutenção do trabalho pode repercutir de maneira positiva para os idosos, contribuindo para a qualidade de vida, prevenção de doenças e na adoção de práticas de autocuidado para manter-se em condições de continuar a desempenhar as atividades do dia a dia, entre elas o trabalho na terra. Outro saber apreendido foi o cuidado a saúde por meio das plantas medicinais, conhecimento repassado de geração em geração.

\section{Cuidar de si com o uso de plantas medicinais: saberes populares}

A prática de utilização das plantas medicinais para tratamento de enfermidades acompanha a história e tradição da humanidade, sendo uma prática extremamente comum e importante até a atualidade, empregada com a finalidade de cura e tratamento de doenças e prevenção de agravos (Mattos et al., 2018). Sabe-se que em tempos de difícil acesso aos serviços de saúde, era comum as pessoas cuidarem da família e dos demais membros da comunidade usando o que aprendiam sobre as plantas medicinais, com chás e infusões caseiras, principalmente.

O meio rural é impregnado de saberes e práticas herdados por meio de experiências vividas no cotidiano, e algumas de difícil formalização sendo, portanto, transmitidas por meios informais de comunicação. Isso advém dos saberes e práticas passados de geração por geração e que não estão escritos em lugar algum, habitando somente as memórias dos sujeitos que as exercitam por meio das práticas cotidianas, conforme evidenciado nas falas a seguir:

"Quando era jovem, não tinha uma preocupação com a saúde, somente depois de algum tempo comecei a me cuidar, de uns 20 anos pra cá, antes nem sabia o que era médico [...] utilizamos bastante chá de mato, ainda hoje prefiro tomar uma xícara de chá do que medicamentos, acredito que é menos prejudicial para a saúde, por ser natural. Tenho essa herança dos meus pais, me ensinaram sobre os tipos, armazenamento e a indicação das plantas, além de como me cuidar" (Gérbera, 70 anos). 
“Com ela (mãe) aprendi o conhecimento referente à utilização de chás, pois minha mãe e a sogra, eram excelentes

"chazeiras", naquele tempo primeiro se tentava resolver a dor em casa com as ervas medicinais, principalmente com o cuidado com as crianças, usávamos a manjerona, funcho, erva doce, camomila e a losna pra dar banho, sempre tínhamos disponíveis e ajudava bastante" (Rosa, 70 anos).

Observa-se que foi por meio das relações familiares que se transmitiam os saberes entre as gerações, dos mais velhos para os mais novos, perpassando desde a indicação, o armazenamento e preparo das ervas. Esses saberes populares podem ser compreendidos como um sistema cultural e de referência identitária, que possibilita uma prática de cuidado e estão repletas de sentimentos, representações, crenças e experiências de vida (Badke et al., 2019). Repassar o saber acumulado entre gerações é um papel social muito importante na comunidade e de grande valoração da pessoa idosa.

Pesquisa realizada por Glowka et al. (2021) sobre o saber popular referente às plantas medicinais em comunidades rurais de um município do Paraná, concluiu que todos os agricultores utilizam as plantas medicinais como primeira forma de tratamento ou cuidado a saúde, com a justificativa que são menos ofensivas ao organismo e porque possuem essas plantas em seus quintais.

Esse saber conduz os idosos ao exercício de um cuidado autorreferido, que ocorre por meio da disseminação do aprendizado, testagem e aperfeiçoamento das práticas, saberes e crenças das pessoas que fazem parte da sua vida. Baseando assim, na experimentação pessoal de saberes disponíveis por meio de experiências anteriores (Contatore; Tesser; Barros, 2021).

Perante a utilização das plantas medicinais e remédios caseiros, a Organização Mundial da Saúde (OMS) reconhece, valoriza e estimula o resgate dessas práticas tradicionais e populares, pois acredita na importância destes saberes e práticas para a promoção da saúde. Ainda, ressalta que $85 \%$ da população utiliza plantas ou preparações para os cuidados básicos de saúde (Brasil, 2016).

Por fim, entende-se que a utilização das plantas medicinais é resultante de um acúmulo secular de saberes empíricos, contudo, a continuidade desse conhecimento que é passado entre as gerações está ameaçada, devido ao êxodo rural, a influência tecnológica, a desqualificação e não reconhecimento desses saberes e práticas pelos profissionais de saúde e a facilidade de acesso a serviços médicos convencionais. É de extrema importância que os profissionais de saúde estabeleçam uma relação pautada no respeito e inclusão dos saberes, experiências, valores e crenças dos idosos para estabelecer ações de promoção da saúde e a integralidade do cuidado.

\section{Gerir o autocuidado em saúde a partir dos saberes formais}

O autocuidado é realizado de forma espontânea e intencional, pautado em saberes socialmente construídos até a tomada de decisão. O cuidado de si envolve questões relacionadas ao autoconhecimento para assumir atitudes positivas para sua saúde, desde o abandono de hábitos antigos, até a adoção de novos modos de vida (Araújo et al., 2018). O autocuidado é uma ação que pode promover o bem-estar, a saúde e favorecer o envelhecimento saudável. Pressupõe-se que os idosos que desenvolvem capacidades para tomar atitudes e fazer escolhas para viver mais e mais saudável, de modo ativo e saudável, com autoestima preservada, são felizes (Almeida; Bastos, 2017).

Conforme Contatore, Tesser e Barros (2021) o autocuidado é realizado por meio de conhecimentos que sustentam práticas vinculadas ao ambiente e grupos sociais onde o sujeito está inserido, o local onde crescem e vivem, além dos saberes repassados e as práticas aprendidas ao longo da vida, tanto de maneira formal quanto informal, como também, por meio dos profissionais de saúde.

Nesta categoria evidenciou-se por meio dos discursos dos colaboradores, que estes valorizam a utilização dos meios de comunicação e as tecnologias relacionais (leves) para obtenção de conhecimentos, como ilustram as falas: 


\begin{abstract}
"O maior acesso às informações contribui para o cuidado com a saúde, elas chegam até nós por meio da televisão, do rádio, trazendo informes até do outro lado do mundo, que nem agora devido a COVID-19. Além, dos programas que trazem instruções sobre saúde, receitas, tratamentos e dicas para uma vida saudável” (Girassol, 75 anos).

"As tecnologias tiveram interferência na nossa saúde também, porque quando você assiste uma entrevista de um médico, de uma enfermeira, ou alguma outra pessoa, que vai explicando sobre os cuidados com a saúde, a gente vai aprendendo e aderindo um pouco, compara com a tua experiência e o que considera válido e interessante acrescenta no dia a dia" (Violeta, 71 anos).
\end{abstract}

"Com a informação aprendemos a cuidar da nossa saúde, seja pelos profissionais da saúde ou pelos meios de comunicação, por exemplo, orientações sobre a exposição solar, o que modificou a rotina da hora de ir para a lavoura, agora vamos mais tarde quando o sol está mais fraco [...]” (Begônia, 73 anos).

"E a gente sempre tem palestras com as enfermeiras e os médicos que falam da importância da movimentação e o cuidar da saúde e com isso vamos modificando nossos hábitos” (Cravo, 73anos).

Estudos enfatizam que os idosos do meio rural normalmente vivem em comunidades mais distantes, o que pode se constituir numa realidade de difícil acesso a programas e atividades organizadas para esse segmento, e que essa população possui uma baixa escolaridade, o que pode colaborar com o menor acesso à informação e aos serviços de saúde (Ness; Hellzen; Enmarker, 2014; Santini; Colussi; Portella, 2019). Nessa direção há que valorar, e muito, as ações realizadas para ampliar e facilitar o acesso as informações necessárias para o autocuidado. As tecnologias leves de cuidado buscam o atendimento humanizado, acolhimento, e criação de vínculo entre o profissional e o usuário (Costa et al., 2016). É por meio desta tecnologia que se constrói e se consolidam boas relações, com troca de informações e orientações que atendam às reais necessidades dos indivíduos, o que influencia o modo de vida e os cuidados com a saúde, na direção de alcançar uma velhice saudável.

O envelhecimento saudável e ativo dos idosos é estabelecido por meio de relações sociais e ações produtivas, além da ausência de doenças e uma boa capacidade funcional. Esse processo de adaptação às mudanças físicas, mentais e sociais vivenciadas ao longo da vida, pode ser considerado como uma forma de manter uma boa velhice (Valer, 2015). Pesquisa realizada por Marinho et al. (2016) que buscou conhecer a percepção dos indivíduos acerca do envelhecimento ativo, evidenciou que estes o compreendem como um equilíbrio biopsicossocial que deve ser garantido por meio da prática de atividades físicas, alimentação saudável, relações com amigos e inclusão social, atividades profissionais e exercícios que estimulem a memória.

De modo geral, a população idosa brasileira está cada vez mais preocupada em manter um estilo de vida saudável, ativo e autônomo. Para que isso ocorra diferentes políticas públicas e programas na área da saúde têm incentivado a população a realizar atividades físicas e a manter-se ativo, enquanto uma prática extremamente importante de promoção de uma vida saudável e com qualidade (Ferretti et al., 2019). Souza, Gonçalves e Gamba (2018) destacam que os programas e projetos de atenção à saúde vinculados a atenção básica, devem priorizar as atividades que promovam a qualidade de vida e se preocupem em manter hábitos que garantam uma velhice saudável, que se configura num novo modo de conscientização.

Para alcançar o envelhecimento saudável e ativo há que se reorganizar a forma de prestar o cuidado, com uma atenção integral que reconheça as particularidades de cada contexto, além disso, as políticas/programas para esse segmento precisam priorizar o cuidado às doenças crônicas e estimular toda ação que promova o envelhecimento saudável, incluindo os idosos na tomada de decisão e no planejamento das ações para seu território, o que resultará em benefícios, não somente para esse segmento, mas também para o sistema de saúde brasileiro, no que se refere a sustentabilidade e qualidade (Veras; Oliveira, 2018; Miranda; Mendes; Silva, 2016).

As ações de educação em saúde, parecem ser um bom caminho para produzir novos saberes para um envelhecer 
saudável, já que a construção de conhecimentos somada ao diálogo em torno das práticas já instituídas, contribui para a autonomia individual e coletiva das pessoas, tornando-se uma excelente ferramenta para a promoção da saúde e qualidade de vida dos idosos (Seabra et al., 2019).

Desta forma, percebe-se que os saberes formais relacionados ao autocuidado em saúde, fizeram com que os idosos assumissem comportamentos preventivos e novos modos de vida, que foram transformados pelos saberes advindos dos meios de comunicação e das atividades organizadas pela atenção básica e profissionais da saúde, que se constituem em importantes canais de disseminação de informação que impulsionam a produção e replicação destes conhecimentos. Os saberes construídos ao longo do viver e envelhecer no contexto rural subsidiaram a tomada de decisão para práticas e comportamentos na direção de um envelhecimento bem-sucedido, logo saudável.

\section{Considerações Finais}

De modo geral, os resultados desse estudo evidenciaram que os idosos moradores do contexto rural construíram os saberes sobre envelhecimento saudável e ativo ao longo da sua trajetória de vida, impregnados de historicidades, constituídos pelas relações sociais, crenças, valores e forte sentimento de pertencimento, de amor e de ligação com o contexto em que vivem.

Dentre os saberes estabelecidos estão à ideia de que a constância do trabalho no meio rural advém de herança familiar e está diretamente relacionado com a manutenção de um perfil mais ativo nas atividades do dia a dia, principalmente nas questões laborais. Além disso, ressaltam a importância da utilização de plantas medicinais no cuidado a saúde. Ainda, valorizam as informações recebidas pelos meios de comunicação e as ações organizadas pelos profisssionais de saúde, já que estes conhecimentos subsidiam a tomada de decisão mais assertiva quanto ao autocuidado e para um envelhecer saudável.

Considerando as lacunas de produção nesse tema, sugere-se a realização de novos estudos para uma melhor compreensão sobre as práticas adotadas pelos idosos para envelhecer de modo saudável e ativo nesse meio, bem como, sobre acesso as ações e serviços de saúde.

\section{Agradecimentos}

Agradeço a Coordenação de Aperfeiçoamento de Pessoal de Nível Superior (CAPES), pelo incentivo, por meio da concessão de bolsa de estudo na realização do Mestrado em Ciências da Saúde.

\section{Referências}

Almeida, L. \& Bastos, P. R. H. O. (2017). Autocuidado do Idoso: revisão sistemática da literatura. Revista Espacios. 38 (28), 3. https://www.revistaespacios.com/a17v38n28/a17v38n28p03.pdf

Araujo, G. M., Leite, M. T., Hildebrandt, L. M., Oliveski, C. C. \& Beuter, M. (2018). Idosos cuidando de si após o diagnóstico de síndrome da imunodeficiência adquirida. Rev. Bras. Enferm, 71(2), 793-800. https://doi.org/10.1590/0034-7167-2017-0248

Badke, M. R., Barbieri, R. L., Ribeiro, M. V., Ceolin, T., Martinez, H. Á. \& Alvim, N. A. T. (2019). Meanings of the use of medicinal plants in self-care practices. Revista da Escola de Enfermagem da USP, São Paulo, 53, n.e03526. https://doi.org/10.1590/s1980-220x2018047903526.

Brasil. Ministério da Saúde (2016). Secretaria de Ciência, Tecnologia e Insumos Estratégicos. Departamento de Assistência Farmacêutica. Política e Programa Nacional de Plantas Medicinais e Fitoterápicos/Ministério da Saúde. Secretaria de Ciência, Tecnologia e Insumos Estratégicos, Departamento de Assistência Farmacêutica - Brasília: Ministério da Saúde,.190 p. http:/bvsms.saude.gov.br/bvs/publicacoes/politi ca_program a_nacional_ plantas_medicinais_fitoterapicos.pdf.

Brasil. Ministério da Saúde (2006). Portaria n o 2.528 de 19 de outubro de 2006. Aprova a Política Nacional de Saúde da Pessoa Idosa. Brasília: Ministério da Saúde. https://bvsms.saude.gov.br/bvs/saudelegis/gm/2006/prt2528_19_10_2006.html.

Brasil. Ministério da Saúde (2005). Organização Pan-Americana da Saúde - Opas - OMS. Envelhecimento ativo: uma política de saúde / World Health Organization; tradução Suzana Gontijo. - Brasília: Organização Pan-Americana da Saúde, 60p. https://bvsms.saude.gov.br/bvs/publicacoes/envelhecimento_ativo.pdf 
Cavalcanti, H. W. V. \& Santos, B. B (2017). The processes of constructing a place-based identity: the experience of residents in the municipalities of Cabo de Santo Agostinho and Ipojuca, Pernambuco, Brazil. Revista Brasileira de Estudos Urbanos e Regionais. Recife, 19 (3), 475-492. https://doi.org/10.22296/2317$1529.2017 \mathrm{v} 19 \mathrm{n} 3 \mathrm{p} 475$

Costa, P. C. P., Garcia, A. P. R. F. \& Toledo, V. P. (2016). Acolhimento e cuidado de enfermagem: um estudo fenomenológico. Revista Texto Contexto Enfermagem, Florianópolis, 25(1), 2-7. http://dx.doi.org/10.1590/0104-07072016004550014

Contatore, A. O., Tesser, C. D. \& Barros, N. F. (2021). Autocuidado autorreferido: contribuições da Medicina Clássica Chinesa para a Atenção Primária à Saúde. Interface, Comunicação, Saúde, Educação, 25(1), 200461. https://doi.org/10.1590/interface.200461

Cruz, P. J. S. C. et a.l (org.). Vivências de extensão em educação popular no Brasil: extensão e educação popular na reorientação da formação em saúde. 2 ed. João Pessoa: Editora do CCTA, 2018. 222 p. http://www.ccm.ufpb.br/vepopsus/wp-content/uploads/2018/02/Viv\%C3\%AAncias-de-Extens\%C3\%A3oem-Educa\%C3\%A7\%C3\%A3o-Popular-no-Brasil-Vol.2-Editora-do-CCTA-2018-1.pdf

Ferraz, L., Alvez, J. \& Ferretti, F. (2017). A vulnerabilidade ocupacional do idoso no meio rural. Saúde e Transformação Social, 8(1), 1-14. https://www.redalyc.org/pdf/2653/265351592007.pdf

French, E. \& Jones, J, B. (2017). Health, health insurance, and retirement: a survey. Annual Reviews of Economy, 9(1), 383-409. https://doi.org/10.1146/annurev-economics-063016-103616

Freire, P (2019). Pedagogia do Oprimido. Paz \& Terra, 256 p.

Freire, P (1984). Ação cultural para a liberdade. 7. ed. Rio de Janeiro: Paz e Terra.

Garbaccio, J. L., Tonaco, L. A. B., Estevão, W. G. \& Barcelos, B. J. (2018). Aging and quality of life of elderly people in rural areas. Revista Brasileira de Enfermagem, Brasília, 71(1), 724-732. http://dx.doi.org/10.1590/0034-7167-2017-0149..

Granerud, A., Imingen, I. \& Eriksson, B. (2017). Everyday Life and Wellbeing among the Oldest Elderly in Norway - A Qualitative Study. Open Journal of Social Sciences. 5(7), 97-111.

Guimarães, G. M. \& Pinheiro, R. (2018). O. Patrimônio cultural e produção artesanal de alimentos: o saber fazer em sistemas de produção da Quarta Colônia. In: Saberes tradicionais e artesanato: expressões culturais do campo brasileiro. David, C.; Vargas, D. L. (Orgs.).

Glowka, K. K. O., Marques, A. S. \& Moura, G. S. (2021). Conhecimento popular sobre plantas medicinais em comunidades rurais do Município de Laranjeiras do Sul, Paraná. Revista Verde de Agroecologia e Desenvolvimento Sustentável, 16(1), 48-59. http://dx.doi.org/10.18378/rvads.v16i1.8423

Mattos, G., Camargo, A., Sousa, C. A. \& Zeni, A. L. B. (2018). Plantas medicinais e fitoterápicos na Atenção Primária em Saúde: percepção dos profissionais. Ciência \& Saúde Coletiva, 23(11), 3735-3744. http://dx.doi.org/10.1590/1413-812320182311.23572016

Mendes, J., Soares, V. M. N. \& Massi, G. A. A. (2015). Percepções dos acadêmicos de fonoaudiologia e enfermagem sobre processos de envelhecimento e a formação para o cuidado aos idosos. Revista CEFAC, São Paulo, 17(2), 576-585. https://doi.org/10.1590/1982-021620153714.

Wincler, M., Boufleuer, T. R., Ferretti, F. \&, Sá, C. A. (2016). Idosos no meio rural: uma revisão integrativa. Estudos Interdisciplinares sobre o Envelhecimento, Porto Alegre, 21(2) 173-194. https://seer.ufrgs.br/RevEnvelhecer/article/view/60691

Tavares, R. E., Jesus, M. C. P., Machado, D. R., Braga V. A. S., Tocantis, F. R. \& Merighi, M. A. B. (2017). Envelhecimento saudável na perspectiva de idosos: uma revisão integrativa. Revista Brasileira de Geriatria e Gerontologia, Rio de Janeiro, $20(6)$, 878-889. https://www.scielo.br/j/rbgg/a/pSRcgwghsRTjc3MYdXDC9hF/abstract/?lang=pt

Tafuri, D. M. \& Gonçalvez, J. L. (2017). Fundamentos teórico conceituais da pesquisa em práticas sociais e processos educativos. Educação Unisinos, São Leopoldo, 21(1), 40-49. https://www.redalyc.org/pdf/4496/449650489006.pdf

Seabra, C. A. M., Xavier, S. P. L., Sampaio, Y. P. C. C., Oliveira, M. F., Quirino, G. S. \& Machado M. F. A. S. (2019). Health education as a strategy for the promotion of the health of the elderly: an integrative review. Revista Brasileira de Geriatria e Gerontologia, 22(4), e190022. https://doi.org/10.1590/198122562019022.190022

Smith, M. K. (1996). What is non-formal education. http://www.infed.org/biblio/b-nonfor.htm

Valer, D. B., Bierhals, C. C. B. K., Aires, M. \& Paskulin, L. M. G. (2015). O significado de envelhecimento saudável para pessoas idosas vinculadas a grupos educativos. Revista Brasileira de Geriatria e Gerontologia, Rio de Janeiro, 18(4), 809-819. https://doi.org/10.1590/1809-9823.2015.14042

Veras, R. P. \& Oliveira, M. (2018). Envelhecer no Brasil: a construção de um modelo de cuidado. Ciência \& Saúde Coletiva. 23(6), 1929-1936. https://doi.org/10.1590/1413-81232018236.04722018. 